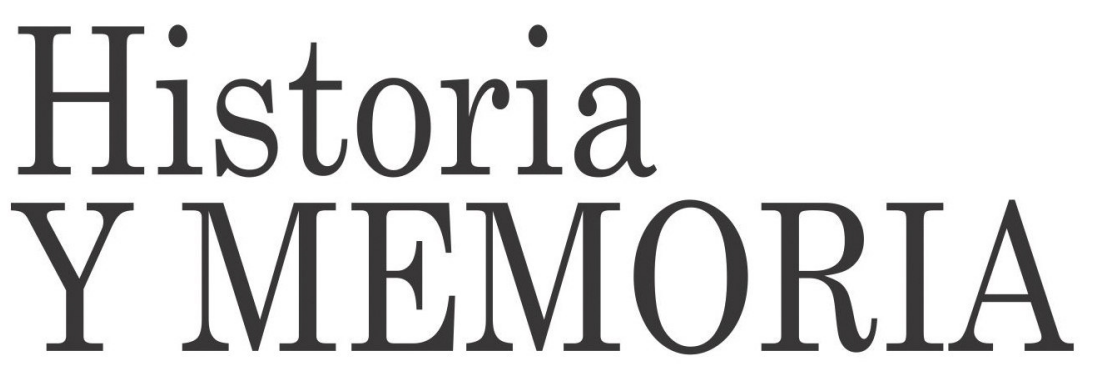

Michel Foucault y la Contra-Historia

José Wilson Márquez Estrada

Páginas: 211 - 243 


\title{
Michel Foucault y la Contra-Historia*
}

\author{
José Wilson Márquez Estrada ${ }^{1}$ \\ Universidad de Cartagena-Colombia
}

Recepción: 01/07/2013

Evaluación: 10/07/2013

Aprobación: 24/10/2013

Artículo de Investigación e Innovación.

\section{Resumen}

En el presente artículo se construye un análisis de la propuesta historiográfica de Michel Foucault y las características de su método genealógico. Igualmente se abordará el problema del sujeto y el concepto acontecimiento dentro del contexto de su propuesta histórica. También se analizará la cuestión del método y su articulación con el oficio específico del historiador que Foucault propone como ejercicio genealógico y arqueológico. En este sentido, se realizará un análisis diferenciador de estos dos conceptos y su papel en la propuesta historiográfica del pensador francés. Igualmente se abordará el tema del sujeto y su importancia en el contexto de la obra de Foucault.

* Este artículo es producto del proyecto de investigación titulado: $L a$ propuesta historiográfica de Michel Foucault, financiado por el grupo de investigación Frontera, Sociedad y Cultura del Caribe y Latinoamérica, del Programa en Historia de la Universidad de Cartagena.

${ }^{1}$ Historiador y Magister en Historia de la Universidad Nacional de Colombia. Abogado de la Corporación Universitaria de la Costa. Profesor Asociado del Programa de Historia, Facultad de Ciencias Humanas, Universidad de Cartagena de Indias. Miembro del grupo de investigación Frontera, Sociedad y Cultura del Caribe y Latinoamérica.jmarqueze@unicartagena.edu.co. 
Finalmente se mostrará el valor de la visión historiográfica foucaultiana dentro del contexto de la historiografía occidental, haciendo énfasis en su posición de ruptura frente a la historia tradicional, ruptura planteada en términos de una contra-historia.

Palabras clave: Genealogía, Arqueología, Historiografía, Historia, Acontecimiento, Episteme, Archivo, Método, Sujeto.

\title{
Michel Foucault and Counter-History
}

\begin{abstract}
This article analyzes the historiographical proposal of Michel Foucault and the characteristics of his genealogical method. Furthermore, the problem of the subject and the concept of event embedded in the context of his historic proposal will be examined. This study encompasses the analysis of important aspects, such as the question of method articulated with the specific role of the Historian, proposed by Foucault as a genealogical and archeological exercise. In this regard, a differential analysis of both of these concepts and their role in Foucault's historiographical proposal will be analyzed; as well as the problem of the subject and its importance in the context of Foucault's work. In the final section, the value of the Foucauldian historiographical vision in the context of the Western historiography will be presented. Emphasis will be placed
\end{abstract}


on its break-up with the traditional history, understood as counter-history.

Key words: Genealogy, Archeology, Historiography, History, Event, Method, Subject, Archive, Episteme.

\section{Michel Foucault et la contre-histoire}

\section{Résumé}

Ce travail analyse le projet historiographique de Michel Foucault et les caractéristiques de sa méthode généalogique. Nous aborderons également le problème du sujet et le concept d'événement dans sa perspective historique. Nous analyserons par la suite la question de la méthode chez Foucault et son articulation avec le métier spécifique d'historien, qu'il conçoit comme un exercice généalogique et archéologique. En ce sens, nous étudierons les différences entre ces deux concepts et leur rôle dans le projet historiographique du penseur français. Nous aborderons également le thème du sujet et son importance dans l'œuvre de Foucault. Finalement, nous montrerons la valeur de la perspective historiographique foucaldienne dans le contexte de l'historiographie occidentale, faisant valoir sa position de rupture vis-à-vis de l'histoire traditionnelle, une rupture posée en termes de contre-histoire.

Mots clés: Généalogie, Archéologie, Historiographie, Histoire, Événement, Épistémè, Archive, Méthode, Sujet. 
"Mis libros no son unos tratados de filosofía ni unos estudios históricos; a lo más, unos fragmentos filosóficos en unos talleres históricos".

Michel Foucault ${ }^{2}$

\section{Introducción}

Michel Foucault es un pensador que se atrevió a proponer una nueva forma de concebir la historia en contravía total con las formas tradicionales y en este sentido construyó toda una propuesta historiográfica revolucionaria caracterizada por el entrecruzamiento de reflexiones desdisciplinares e interdisciplinares donde se encuentran la filosofía, la sociología, la psicología social y la historia. Es desde la filosofía donde Foucault plantea su propuesta historiográfica, haciendo de ella un ejercicio enteramente político y totalmente historiador. Foucault es el fundador de una nueva tradición historiográfica cuya preocupación central es mostrar las relaciones sujeto-verdad y qué tipo de poder es susceptible de producir discursos de verdad en una sociedad como la nuestra, discursos dotados de poderosos efectos sobre los individuos y colectivos humanos. En este sentido, en el universo de sus investigaciones, empiezan a aparecer objetos de estudio como la locura, la sexualidad, el castigo, el cuerpo, el deseo, la sociedad disciplinaria, buscando desobjetivizar estos objetos. Una historiografía donde los protagonistas son los marginados sociales: los locos, los criminales, los homosexuales, los anormales, los enfermos. Una historiografía preocupada por descifrar los discursos de verdad que han tratado de consolidar en occidente toda una ortopedia social destinada a corregir los males de la sociedad y de la cultura burguesas. Para desarrollar este proyecto Foucault propondrá un método

${ }^{2}$ Jacques Leonard, "El Historiador y el Filósofo", en: La Imposible Prisión. Debate con Michel Foucault, (Barcelona: Cuadernos Anagrama, 1982), 57. 
totalmente innovador, un método que le permitirá desentrañar temas y reflexionar sobre cuestiones que nunca habían sido objeto de estudio de los historiadores: ese método será la genealogía.

En la reflexión historiográfica foucaultiana se encuentra el problema de la verdad como el eje articulador de todo su discurso historiográfico. En este orden de ideas, todo tipo de verdad en occidente es puesto bajo la óptica de la sospecha y bajo la lente de la mirada crítica del pensador francés: "Pronto comprenderán que la historia de Occidente no se puede disociar del modo en que la "verdad" se produce e inscribe sus efectos. Toda sociedad tiene regímenes de verdad, pero hay muchos tipos de relación con la verdad. Vivimos en una sociedad que produce y pone en circulación discursos que cumplen función de verdad que pasan por tal y que encierran gracias a ello poderes específicos. Uno de los problemas fundamentales de Occidente es la instauración de discursos "verdaderos", (discursos que, por otra parte, cambian incesantemente)". ${ }^{3}$ Discursos que se organizan en positividades.

El pensamiento de Nietzsche ocupa un papel preponderante en la obra de Foucault y es a través de este pensador alemán que proyecta su propuesta historiográfica. Foucault entra a la obra de Nietzsche a partir de la experiencia que le dejó la construcción de su tesis doctoral sobre la historia de la locura en la época clásica ${ }^{4}$, entendiendo como época clásica la modernidad. Foucault en esta investigación encuentra el camino de hacer imposible ciertos gestos de la racionalidad en occidente y esto lo

\footnotetext{
${ }^{3}$ Michel Foucault, "No al sexo rey. Entrevista por Bernard Henry-Levy", En Un diálogo sobre el poder y otras conversaciones, (Madrid: Alianza Editorial, 1981), 148.

${ }^{4}$ Michel Foucault ,Histoire de la folieà l'age classique, (París: Plon, 1964). Primera edición en español: Historia de la locura en la época clásica, (México: F.C.E., 1967).
} 
conduce a Nietzsche, quien en El crepúsculo de los ídolos, hablaba de la deconstrucción de la cultura por medio de la inversión de la racionalidad. ${ }^{5}$ Foucault a partir de este encuentro empieza a erigir su propuesta historiográfica fundada en la negación del valor clásico de la historia como tal, a pesar que en La arqueología del saber muestra su deuda con los Annales, proponiendo otra forma de hacer historia, historia entendida como juego de poder. Foucault construye un universo lingüístico para el abordaje de la historia, conceptos que permiten la arquitectura de toda una red de exploración histórica tales como archivo, episteme, enunciado, discurso, acontecimiento, dispositivo, los cuales han enriquecido y abierto la esfera de sentido y el hipertexto del discurso historiográfico en occidente. Conceptos que permiten visibilizar las diferentes redes intrínsecas y los profundos niveles de la realidad histórica.

En el presente artículo se plantea hacer un análisis de la propuesta historiográfica de Michel Foucault y las características de su método genealógico. El artículo está dividido en cuatro partes: en la primera se tratará el problema del sujeto, en la segunda se analizará el concepto de acontecimiento, en la tercera se abordará el problema del método y en la cuarta parte se analizará el tema de la genealogía. Finalmente el texto se cierra con unas consideraciones finales.

\section{El problema del sujeto en Michel Foucault}

Con relación al proceso de construcción del sujeto, Michel Foucault ha encontrado habitualmente en Francia que la tradición marxista universitaria ha partido casi siempre del supuesto que éste no es más que el depositario de

5 José Luís Moreno, Convirtiéndose en Foucault. Sociogénesis de un filósofo, (Madrid: Montesisnos, 2006), 101. 
todas unas condiciones económicas y sociales que se incorporan en el individuo. Foucault por el contrario ha demostrado, especialmente para el siglo XIX, que el sujeto en tanto individualidad, surge como consecuencia de unos mecanismos de control y vigilancia. ${ }^{6}$ Este proceso de construcción del sujeto en occidente está conectado con los procesos de construcción de verdad que paulatinamente fueron colocando al hombre en el centro de sus reflexiones y es por esto que Foucault plantea que el hombre es una invención reciente:

Me gustaría mostrar en particular cómo pudo formarse en el siglo XIX un cierto saber del hombre, de la individualidad, del individuo normal o anormal, dentro o fuera de la regla; saber éste que, en verdad, nació de las prácticas sociales de control y vigilancia. Y cómo, de alguna manera, este saber no se le impuso a un sujeto de conocimiento, no se le propuso ni se le imprimió, sino que hizo nacer un tipo absolutamente nuevo de sujeto de conocimiento. $^{7}$

Resaltando que esta es sólo la mirada genealógica, que hay que cruzarla con la mirada arqueológica (sujeto de saber) y con la ética (coraje de la verdad), esto lo articula Foucault con los conceptos de objetivación/subjetivación.

Foucault encuentra en Nietzsche la posibilidad de pensar el surgimiento del sujeto como efecto de discursos de saber, como una "invención" para no decir "origen" y afirma: "Creo que en Nietzsche se encuentra un tipo de discurso en el que se hace el análisis histórico de la formación misma del

${ }^{6}$ Elías Castro Blanco, "Foucault y los estudios historiográficos", Criterio Jurídico Garantista 1. Fundación Universidad Autónoma de Colombia. Barranquilla. (Junio de 2009), 92-109.

${ }^{7}$ Michel Foucault, La verdad y las formas jurídicas, (Barcelona: Gedisa, 2005), 12 . 
sujeto, el análisis histórico del nacimiento de un cierto tipo de saber, sin admitir jamás la preexistencia de un sujeto de conocimiento". ${ }^{8}$ En este orden de ideas, el surgimiento del sujeto debe ser entendido como una invención producto de unos dispositivos de saber $^{9}$ y no como efecto de una creación consciente de los hombres. Foucault plantea que el sujeto hay que redescubrirlo, darle su lugar en la historia y ubicarlo, en la órbita de lo sexual y de lo mental, por ejemplo. En este sentido, Foucault propone una crítica radical a las denominadas ciencias humanas que han pensado al hombre como ser vivo, hablante y producente, nunca reconociéndolo como sujeto: "En efecto las ciencias humanas se dirigen al hombre en la medida en que vive, en que habla y en que produce. (...) Así, pues, es posible fijar el sitio de las ciencias del hombre en la vecindad, en las fronteras inmediatas y todo a lo largo de esas ciencias en las que se trata de la vida, del trabajo y del lenguaje". ${ }^{10}$ A partir de esta crítica a las ciencias humanas Foucault habla de la "muerte del hombre", el hombre como una invención reciente y con un próximo fin, tragedia que se aborda en cuatro aspectos: el proceso previo de invención epistémica del hombre que ella supone, el carácter hipotético de la desaparición del hombre, la naturaleza inacabada de tal proceso y la dimensión de apertura que se halla involucrada en dicho acontecimiento. ${ }^{11}$ Esa crítica de Foucault a las ciencias humanas se extiende inclusive al humanismo; por ejemplo, en una entrevista en

\footnotetext{
${ }^{8}$ Michel Foucault, La verdad y las formas jurídicas,... 18.

${ }^{9}$ Para Foucault un dispositivo es una red, es decir, un conjunto decididamente heterogéneo, que comprende discursos, instituciones, instalaciones arquitectónicas, decisiones reglamentarias, leyes, medidas administrativas, enunciados científicos, proposiciones filosóficas, morales, filantrópicas; en resumen, los elementos del dispositivo pertenecen tanto a lo dicho como a lo no dicho. El dispositivo es la red que puede establecerse entre estos elementos. Luís. Garcia Fanlo, "Qué es un dispositivo?: Foucault, Deleuze, Agamben.” A Parte Rei74. (Marzo 2011), 1-8.

${ }^{10}$ Michel Foucault, Las palabras y las cosas, (Madrid: Siglo XXI, 1999), 341.

${ }^{11}$ Rodrigo Castro Orellana, "La frase de Foucault: "el hombre ha muerto", Alpha 21, (Diciembre de 2005), 225-233.
} 
la Universidad de Massachusetts en 1982, al respecto dice lo siguiente:

El humanismo ha sido utilizado por marxistas, liberales, nazis, católicos. Lo que me asusta del humanismo es que presenta cierta forma de nuestra ética como modelo universal para cualquier tipo de sociedad. Me parece que hay más secretos, más libertades posibles y más invenciones en nuestro futuro de lo que podemos imaginar en el humanismo $[\ldots]^{12}$

Foucault ubica a la historia como la primera y madre de todas las ciencias del hombre: "En efecto, quizá no tiene un lugar entre las ciencias humanas ni al lado de ellas: es probablemente que mantenga con todas ellas una relación extraña, indefinida, imborrable y más fundamental de lo que sería una relación de vecindad en un espacio común". ${ }^{13}$ En este panorama, la historia ha existido mucho antes de la constitución de las ciencias humanas; desde el fondo de la época griega, ha ejercido diferentes funciones en el contexto de la cultura occidental: memoria, mito, vehículo de tradición, conciencia crítica del presente, desciframiento del destino de la humanidad. ${ }^{14}$ Igualmente la historiografía científica fundada en el siglo XIX, concentrada en macroprocesos, estableciendo contactos y diálogos con todas las ciencias sociales en el siglo XX, con todas sus emociones y temores, a excepción de ciertos historiadores de la escuela francesa de los Annales, son pocos los historiadores que han indagado en las profundidades del sujeto. ${ }^{15}$ Pero a Foucault no le interesan esas profundidades del sujeto sino más bien sus planos de inmanencia o superficies de emergencia.

\footnotetext{
${ }^{12}$ Michel Foucault, Las palabras y las cosas,... 356.

${ }^{13}$ Michel Foucault, Las palabras y las cosas,... 356.

${ }^{14}$ Michel Foucault, Las palabras y las cosas,... 357.

${ }^{15}$ Reinaldo Giraldo Díaz, "la ética en Michel Foucault o de la posibilidad de la resistencia”, Dialogo de saberes 29. (Diciembre de 2008), 201-213.
} 
Foucault por medio del análisis histórico demostró que el sujeto no es una unidad eterna, sino que está inscrito en un régimen de historicidad. Víctor Gutiérrez plantea al respecto lo siguiente:

En prácticamente todos sus libros con excepción de La arqueología del saber existe la iniciativa de analizar la configuración de cierto tipo de sujeto ya haya sido en relación a la verdad que lo constituye como objeto de conocimiento, la iniciática de observar el poder como constituyente del sujeto que actúa ante los demás, así como una relación ética por medio de la cual el individuo se constituye como sujeto de acción moral. ${ }^{16}$

Foucault entonces consideró al sujeto no como un ser en concreto sino como un haz de funciones relacionales y posicionales. Problematización que se instala en la historia de las formas del sujeto, es decir, en los modos de subjetivación. Es claro para Foucault que el sujeto se encuentra instalado en juegos de verdad a través de prácticas como la psiquiatría, el sistema penitenciario, o en una ciencia, en un modelo científico, en las instituciones, entre muchas otras. En síntesis, esto quiere decir que hay modos de ser del sujeto que depende de su forma de constituirse a través de los juegos de verdad y de las prácticas de poder. Foucault rompe con la idea de la existencia previa del sujeto, para él los sujetos se constituyen al interior de regímenes de verdad, en los que ciertos discursos tienen un papel medular. En este contexto, no existen discursos inertes ni un sujeto todopoderoso que los manipule, sino que los sujetos forman parte del campo discursivo con una posición y función específicas. ${ }^{17}$

\footnotetext{
${ }^{16}$ Víctor Iván Gutiérrez Maldonado, Las transformaciones de las diversas concepciones del sujeto en La arqueología del saber, (Tesis de Maestría en Historia, Universidad Autónoma Metropolitana, México, 2012), 118.

17 Javier Torres, Notas para leer al Sujeto en Foucault desde América Latina, Disponible en: http://alainet.org/active/20042\&lang=es
} 


\section{El concepto de Acontecimiento en Michel Foucault.}

Foucault en La arqueología del saber nos habla de dos formas de construir el texto historiográfico, a partir de dos tipos de análisis de la historia: la forma tradicional hace énfasis en la continuidad de las grandes unidades históricas y la nueva forma de hacer historia, que por el contrario, instala su análisis en descubrir las interrupciones que corren por debajo de unidades históricas. Ambas formas historiográficas operan con documentos y su valoración del documento es diferente, mientras la primera lo indaga para reconstruir el pasado que lo produjo, la historia nueva no pretende ni interpretarlo ni probar su veracidad sino abordarlo desde su interior. ${ }^{18}$ En esta perspectiva, la historia nueva plantea una posición revolucionaria con respecto a la utilización del documento ya no se asume como un ente muerto sino como una entidad llena de vida: "la historia ha cambiado de posición respecto del documento: se atribuye como tarea primordial, no el interpretarlo, ni tampoco determinar si es veraz y cual sea su valor expresivo, sino trabajarlo desde el interior y elaborarlo". ${ }^{19}$ Este giro revolucionario con relación al documento implica una transformación epistemológica fundamental para la historiografía, que consiste en asumir ya no el documento como memoria sino como monumento, compitiéndole al investigador desplegar sobre él una actividad hermenéutica diferente de reelaboración semiológica donde el documentos ya no sólo se muestre por fuera sino por dentro, en lo que aparentemente no dice, estableciendo unidades, conjuntos, series, relaciones: "Hay que separar la historia de la imagen en la que durante mucho tiempo se complació y por medio de la cual encontraba su justificación antropológica: la de

\footnotetext{
18 Lisandro de la Fuente y Luciana Messina, "Bajos fondos del saber. La arqueología como método en Michel Foucault.", Litorales Año 2, No. 2, (Agosto 2003), 1-11.

${ }^{19}$ Michel Foucault, La arqueología del saber, (Madrid: Siglo XXI, 2006), 10.
} 
una memoria milenaria y colectiva que se ayudaba con documentos materiales para recobrar la lozanía de sus recuerdos(...)" ${ }^{20}$ Simultáneamente y bajo esta misma perspectiva Foucault plantea entonces una nueva forma, igualmente revolucionaria, para entender la historia, no ya en el sentido plano y lineal como la planteaba la historia tradicional, sino en un sentido ruptural, es decir, en el sentido donde lo que importa son los pliegues, las fisuras, los cortes, los quiebres, la ruptura y para ello se hace necesario replantear un concepto que nos permita entender dichas fracturas en la historia, ese concepto es el de acontecimiento. ${ }^{21}$ El acontecimiento como instancia singular y práctica para el análisis de la historia que se inscribe en el estudio sobre la concurrencia en un momento determinado de conexiones, estrategias, apoyos, bloqueos y juegos de fuerza y de poder, que han dado lugar a una emergencia singular en la historia, extraña y rara donde aflora un terreno intenso de fuerzas y contra-fuerzas donde lo múltiple se pliega sobre sí. ${ }^{22}$ Lo importante para Foucault es detener la mirada en la rareza del evento, en la originalidad del acaecer; en ruptura total con la historiografía tradicional que asumía los acontecimientos en relación a una serie de afirmaciones presupuestas, propias de los análisis positivistas de la época donde al acontecimiento aparece como un haber sido absoluto, es decir, como un hecho absolutamente pasado. En esta representación, hacer la historia era conocer las acciones humanas pretéritas creándose un muro infranqueable que nos negaba el acceso a la comprensión de lo extraño. Esta nueva mirada del acontecimiento en Foucault tiene unos encuentros innegables con la escuela

\footnotetext{
${ }^{20}$ Michel Foucault, La arqueología del saber,... 11.

${ }^{21}$ En "El polvo y la nube" dice que él no es discontinuista, sino que estudia la relación continuo/discontinuo. Cfr., Michel Foucault, El polvo y la nube, En: La imposible prisión, (Barcelona: Ed. Anagrama, 1982).

22 Santiago Díaz, "Foucault y Veyne. Los usos del acontecimiento en la práctica histórica.”, A Parte Rei No.69, (Mayo de 2010), 1-20.
} 
francesa de los Annales, quienes fueron los pioneros en construir una mirada innovadora del acontecimiento no como un ente sino como construcción del historiador, lejos de la visión positivista del acontecimiento como hecho absoluto. ${ }^{23}$

Foucault propone entonces una nueva mirada, una mirada arqueológica que se sumerja en las profundidades del acontecimiento para penetrar las capas subterráneas que subyacen bajo la superficie de los mismos, para desentramar las relaciones de saber, de poder y de verdad que los soportan. Foucault irrumpe entonces en la historiografía occidental con la tematización del poder, del saber y de los juegos de verdad en el ámbito de la medicina, la psiquiatría, la sexualidad y la prisión, en un contexto donde la historia de las mentalidades se hallaba instalada en los temas de la antropología social. Santiago Díaz plantea al respecto que:

No hay duda en que Michel Foucault contribuyó de enorme manera a la historia y, más específicamente, a sus modos de aproximarse al tratamiento de los hechos históricos. Los temas tratados, la forma en que estos eran presentados y la rehabilitación de la instancia en el discurso como lugar de producción de la realidad, contribuyeron a que Foucault brindara buenos aportes a las reflexiones críticas de los historiadores. Aunque en muchas entrevistas él aclara explícitamente que no es un historiador, ni siquiera un filósofo, y que el objetivo de sus investigaciones no es la historia y sus hechos en sí mismos, sino que lo que le interesa es establecerse en los acontecimientos

\footnotetext{
${ }^{23}$ Véase Fernand Braudel, La historia y las ciencias sociales, (Madrid: Alianza, 1970). Braudel plantea todo un enfoque innovador del acontecimiento en la historia, entendido como un efecto de superficie en los que los agentes de acción son múltiples, los acontecimientos son "crestas de espuma que las oleadas de la historia llevan sobre sus poderosos lomos", p. 64.
} 
de la historia para indagar en lo profundo de esas emergencias en función del sujeto y de la verdad. ${ }^{24}$

La propuesta historiográfica de Michel Foucault está definitivamente instalada en la idea de una ontología del presente, de nosotros mismos, de fragmentos existenciales, de huellas silenciosas, de relatos de vida pequeños, casi insignificantes, de sujetos invisibles como los homosexuales, los locos o los criminales. Con Foucault asistimos a un giro epistemológico revolucionario en la historiografía occidental, un giro marcado por la problematización de los pequeños trozos de la historia, donde el desequilibrio y la inestabilidad son los elementos comunes del acontecer cotidiano. No es una recuperación de lo no visto, es una nueva mirada a las objetivaciones/subjetivaciones: lo decible y lo enunciable. Foucault plantea en esta nueva indagación arqueológicagenealógica un nuevo tipo de racionalidad, donde se pone de manifiesto la contingencia de las significaciones, donde lo que importa ya no es la continuidad ni la tradición sino el recorte y el límite que nos permita pensar la discontinuidad. En este sentido Foucault nos propone una red de conceptos dónde poder atrapar la discontinuidad, dónde poder problematizarla, esos conceptos son: umbral, ruptura, corte, mutación, transformación. En esta imagen se nos aparece un Foucault con su equipo de arqueólogo buscando las discontinuidades en el ancho y vasto territorio de la historia, esta sería entonces para Foucault la nueva imagen del historiador.

La noción de acontecimiento se encuentra ligada a la noción de "irrupción" en el sentido de un quiebre dela continui$\operatorname{dad}^{25}$ y en un todo opuesta a ésta. El acontecimiento se debe

\footnotetext{
${ }^{24}$ Santiago Díaz, "Foucault y Veyne. Los usos del acontecimiento en la práctica histórica”,... 7.

${ }_{25}$ Sergio Albano, Michel Foucault. Glosario epistemológico, (Buenos Aires: Editorial Quadrata, 2006), 31. Según Albano, para Foucault la continuidad es el conjunto o masa de nociones que consiste en considerar la historia como una sucesión uniforme y continua de series temporales y espaciales que arrastra a todos los seres y objetos a un mismo devenir y en una misma dirección.
} 
entender como la emergencia de lo singular que se opone a la regularidad discursiva construida por los operadores de la continuidad. Al respecto, Sergio Albano opina lo siguiente:

El acontecimiento es siempre la expresión de un proceso silencioso del cual emerge en un momento determinado; su rasgo fundamental es la singularidad, su carácter irrepetible. La emergencia de un acontecimiento depende de las condiciones materiales del discurso, del estado de sus agrupamientos, de sus vecindades. ${ }^{26}$

La crítica de Foucault es a la historia concebida como lineal, como progresiva, como totalizante, es decir, es una crítica a la comprensión de la historia monumental y suprahistórica. $^{27}$ La emergencia del acontecimiento se origina en un cierto estado de fuerzas, donde no hay protagonistas ni responsables, que debe ser entendida como efecto de sustituciones, emplazamientos y desvíos sistemáticos. ${ }^{28}$ Interpretar la historia es comprender el

${ }^{26}$ Sergio Albano, Michel Foucault. Glosario epistemológico,... 35.

${ }^{27}$ En una conocida expresión, Foucault indicaba que su interés radicaba en la historia del presente y no en la del pasado en términos del presente. Entender las emergencias, despliegues y transformaciones que han constituido nuestro presente es lo que mueve el trabajo de Foucault. A eso llama historia del presente. Esta historia se opone a una historia desde el anacronismo, desde el presentismo histórico que hace una historia del pasado en términos del presente. Este anacronismo o presentismo históricos operan de formas sutiles, pero efectivas. Se articulan a partir de los procedimientos deseventualizantes y de la indagación metafísica que circulan ampliamente en la práctica investigativa de quienes, por disímiles motivos, apelan al pasado. Este estudio del pasado en términos del presente supone una violencia epistémica sobre horizontes de historicidad más o menos ajenos a los que operan en el presente. En sus expresiones más burdas, constituye una verdadera aplanadora de las densidades y singularidades históricas obliterando cualquier posibilidad de comprensión no sólo de lo referido en el pasado, sino también de las condiciones de posibilidad y supuestos del propio presente. La eventualización como principio de inteligibilidad histórica es la propuesta de método que uno encuentra en Foucault para evitar las trampas del presentismo histórico y de la indagación metafísica. Eduardo Restrepo, "Cuestiones de Método.", Tabula Rasa, 8 (2008), 111.

${ }^{28}$ Michel Foucault, Microfísica del poder, (Madrid: Ediciones La Piqueta, 1992), 14. 
sentido de dominación imperante en las reglas que están en boga en un determinado momento. ${ }^{29}$ Interpretar un acontecimiento implica entenderlo en el contexto no de una duración sino de una multiplicidad de duraciones que se entremezclan y se envuelven unas en otras, resultado de una labor historiográfica que permita hacer surgir y visibilizar los puntos de ruptura con sus capas de discursos, estrategias de poder y focos de resistencia. Este proceso de elaboración historiográfica lo llama Foucault eventualización ${ }^{30}$, trabajo de laboratorio historiográfico que consiste en mostrar la irrupción de una singularidad, que implica necesariamente un proceso de desmantelamiento profundo que permita hacer visible la relación de fuerzas que posibilitan la emergencia del acontecimiento. Emergencia que se puede rastrear en los juegos del lenguaje cuando irrumpen conceptos que realizan una marca en el universo de las prácticas sociales en un momento determinado, por ejemplo, categorías como loco, depravado, anormal, criminal están conectadas con las prácticas divisorias de encierro. Este proceso de abordaje del acontecimiento no es un acto singular sino un ejercicio encadenado de prácticas de archivo y documento en la compleja cartografía histórica repleta de singularidades emergentes. El acontecimiento entendido como la irrupción de una singularidad histórica en la pluralidad de los aconteceres históricos. ${ }^{31}$

Para Foucault construir una historia efectiva implica una desgarradura que nos permita el desligamiento de los procesos de continuidad y la instalación definitiva en el campo de fuerzas de la historia donde se presencia el quiebre, el choque y las tensiones que produce las

\footnotetext{
${ }^{29}$ Santiago Díaz, "Foucault y Veyne. Los usos del acontecimiento en la práctica histórica”,... 11.

30 Michel Foucault, El discurso del poder, (Buenos Aires: Folios Ediciones, 1992), 220.

31 Santiago Díaz, "Foucault y Veyne. Los usos del acontecimiento en la práctica histórica”, ,..12.
} 
erupciones del acontecimiento. Una historia de múltiples rostros, una historia sin protagonistas, una historia sin sujeto. El reto para el historiador es salir de la prisión de esa forma de pensar la historia desde la perspectiva de la evolución, la linealidad y la conciencia ${ }^{32}$ y situarse definitivamente en el terreno de la discontinuidad y la ruptura como en un campo de batalla:

La ruptura no es un tiempo muerto e indiferenciado que se intercale -siquiera fuese por un instanteentre dos fases manifiestas; no es el lapso sin duración que separe dos épocas y desplegase de una y otra parte de una fisura, dos tiempos heterogéneos; es siempre entre unas positividades definidas, una discontinuidad especificada por cierto número de transformaciones distintas..$^{33}$

El objetivo para Foucault es hacer de la historia una contramemoria y hacer desplegar por consiguiente otra forma de tiempo. ${ }^{34}$ Una historia sin sentido histórico, sin coordenadas, sin universales antropológicos. Una historia sin el peso de gravedad de la causalidad, pero con el rigor de una "desmultiplicación causal", una historia de los bordes. ${ }^{35}$

\footnotetext{
32 Antonio Restrepo Arango, Pensar la historia, (Medellín: Ediciones Stendhal, 2000), 162.

${ }^{33}$ Michel Foucault, La arqueología del saber,... 293.

${ }^{34}$ Michel Foucault, "Nietzsche, la genealogía, la historia.", Sociología 5, UNAULA, (Diciembre de 1983), 5-23.

${ }^{35} \mathrm{El}$ interés de la historia subterránea excluida por la historia tradicional, se acrecentó a partir de la década del setenta. Así pues las obras de Foucault no se presentan como hechos aislados si se mira la producción de la época. E. J. Hobsbawm, publicó Rebeldes primitivos en 1959; en Norteamérica Eugenio Genovese trabajó el problema de la esclavitud, en 1956 apareció su Economía política del esclavismo. En Inglaterra Christopher Hill publicó en 1972 El mundo trastornado, El ideario popular extremista en la revolución inglesa del siglo XVII; en esta misma época aparecen las obras de E. P. Thompson, Tradición, revuelta y conciencia de clase. En el mismo año en que publica Vigilar y castigar, en 1975, aparece la gran investigación de Emmanuel Le Roy Ladurie, Montaillou, aldea occitanna de 1224 a 1324. Antonio Restrepo Arango, Pensar la historia, 165. Igualmente es necesario destacar el triple uso de la categoría de ruptura en Foucault planteado en la Arqueología del saber.
} 


\section{El método en Michel Foucault.}

Una de las máximas preocupaciones de Foucault en el contexto intelectual de mayo del 68 era diseñar una metodología que lograra sortear algunos de los obstáculos que había observado en algunas expresiones teóricas como el marxismo, el psicoanálisis, el existencialismo, la fenomenología, al igual que algunas corrientes historiográficas. Las discusiones sobre los efectos políticos de estas teorías estaban a la orden del día y la famosa frase: "las estructuras no bajan a la calle", caracterizaba el momento político de la época. ${ }^{36}$ En este sentido Foucault propone en la Arqueología del saber un método de análisis de la historia totalmente innovador que consiste en una crítica de los grandes temas de la historia de las ideas (unidad, continuidad, totalidad, origen) y al abordar los documentos como restos arqueológicos, se detiene en el estudio de las reglas de formación de los discursos y de sus discontinuidades, permitiendo la descripción del espacio de dispersión de los saberes. ${ }^{37}$

Los trabajos de Foucault se soportan en el análisis de los materiales históricos y en un nuevo concepto de archivo:

En lugar de ver alinearse, sobre el gran libro mítico de la historia, palabras que traducen en caracteres visibles pensamientos constituidos antes y en otra parte, se tiene, en el espesor de las practicas discursivas, sistemas que instauran los enunciados como acontecimientos (con sus condiciones y su dominio de aparición) y cosas (comportando su posibilidad y su campo de utilización). Son todos esos sistemas de enunciados (acontecimientos por

\footnotetext{
${ }^{36}$ Fernando Beresñak, "Michel Foucault y su metodología histórico-filosófica", Revista Digital Synesis 2 Mar del Plata (Primavera 2011), 8-33.

${ }^{37}$ Lisandro de la Fuente y Luciana Messina, "Bajos fondos del saber... 5. 
una parte, y cosas por otra) los que propongo llamar archivo. ${ }^{38}$

En síntesis, entendemos que hay una ley que rige, agrupa, mantiene y dispersa lo que puede ser dicho. A esta ley Foucault la denomina archivo; entonces en tiempos diferentes, diferentes archivos permiten diferentes enunciados. Esto obliga a redefinir lo que entiende Foucault por fuente: no debe haber fuente privilegiada, hay que leerlo todo, conocer todas las instituciones y todas las prácticas, teniendo en cuenta que hasta los elementos inconscientes hacen parte del discurso histórico. ${ }^{39}$

Con relación al material de trabajo, Foucault distingue entre textos teóricos y no teóricos, estos últimos tienen su origen en las instituciones y tienen una fuerte repercusión en la esfera de la vida de los individuos: registros médicos, reportes judiciales, reglamentos institucionales reflejan la vida interna de los sujetos en estos establecimientos. Los textos teóricos hacen referencia a textos que tienen prescripciones, reglas, consejos que funcionan como operadores para ser leídos, aprendidos, meditados y utilizados. $^{40}$ Con relación al tratamiento del documento para Foucault, es claro que no se trata de ninguna manera de interpretarlo sino de elaborarlo, estableciendo series de acontecimientos, fijando sus elementos intrínsecos, estableciendo sus límites y sus relaciones con otras series. Estas correlaciones establecidas no se apoyan en las antiguas filosofías de la historia, sino que tienen por fin revisar las teleologías y las totalizaciones racionales y romper con la idea de intentar restaurar una memoria

\footnotetext{
${ }^{38}$ Michel Foucault, La arqueología del saber, 219.

${ }^{39}$ Véase Edgardo Castro, Pensar a Foucault: interrogantes filosóficos de La arqueología del saber, (Buenos Aires: Biblos, 1995).

40 Fernando Beresñak, "Michel Foucault y su metodología históricofilosófica”,... 14.
} 
humana.$^{41}$ Foucault es definitivamente un investigador de terreno, un hombre de archivos, es decir, un documentalista, que planteó una nueva forma de entrarle al documento, no únicamente por lo que dice sino especialmente por lo que no dice, planteando una nueva semiología de documento, valorándolo en su total integridad e instalándolo en el contexto relacional de su tiempo y no tratarlo como un vestigio del pasado sino como un "monumento", esto es como un campo relacional. Por esto Foucault es llamado "el nuevo archivista, el nuevo cartógrafo". ${ }^{42}$ Para él, el archivo era una realidad en permanente definición y como dice Renán Silva:

Foucault designaba con el nombre preciso de "archivo" una realidad que no dejó de redefinir y que tiene consecuencias importantes que me merece que en el campo de la investigación histórica no hemos terminado de comprender y asimilar, una contribución mayor a los enfoques y métodos de las "historias intelectual y cultural" que seguirá teniendo en la Arqueología del saber su expresión más notable y tal vez más cifrada y condensada. ${ }^{43}$

Un nuevo cartógrafo que promovió la idea de traer la palabra olvidada a la escena de la historia mostrando otras existencias ejemplares en sentido inverso de las convenciones sociales, recordándonos que el sufrimiento existe por todas partes en la sociedad, instalando su pensamiento en el límite, concentrándose en esos "agujeros negros" cuya realidad nos negamos a pensar. ${ }^{44}$ Foucault

\footnotetext{
${ }^{41}$ Santiago Díaz, "Foucault y Veyne. Los usos del acontecimiento en la práctica histórica”, ... 17.

${ }^{42}$ Véase Gilles Deleuze, Foucault, (Barcelona: Paidós, 1987).

${ }^{43}$ Renán Silva Olarte, "En defensa de un positivismo alegre. Michel Foucault en el archivo", Revista Historia y memoria No. 4, (Diciembre de 2012), 225-257.

${ }^{44}$ Renán Silva Olarte, "En defensa de un positivismo alegre. Michel Foucault en el archivo", ... 238.
} 
propone romper los límites de la reflexión habitual de los historiadores y conducirlos a zonas de desgarramiento donde se visibilicen los silencios de la historia. Un trabajo de cartógrafo en las sombras de la historia subterránea, de la historia de seres humanos jamás reconocidos por la historia tradicional. ${ }^{45}$ Dándole un nuevo perfil al trabajo del historiador que no se limite al análisis y rescate de documentos sin enfrentar el problema de las formas de relación, de génesis y de evolución de un grupo determinado de acontecimientos, verdadero objeto del análisis histórico. ${ }^{46}$

Para Foucault la relación saber poder es el trasfondo principal de cualquier tipo de indagación historiográfica y por eso es tarea primordial del historiador ubicar bajo esta relación cualquier hallazgo material o documental. Con relación al saber, Foucault plantea que el saber de una época se halla constituido por el conjunto de los regímenes de enunciados posibles, regímenes que encuentran sus límites en lo visible y lo indecible en un tiempo y lugar determinados y que resultan del juego de reglas que permiten su emergencia. ${ }^{47}$ El saber para Foucault es aquel pensamiento implícito en la sociedad (entendida esta no como totalidad ontológica explicativa), un pensamiento anónimo constituido a partir de cierta relación de fuerzas de poder y de reglas de formación, que se configura como condición de posibilidad de cualquier teoría o práctica científica. Entonces el saber de una época se visibiliza en las prácticas sociales y se deja palpar en los quehaceres institucionales y aparecen ante los ojos del historiador en los reglamentos,

45 Michel Foucault, Yo Pierre Riviere, habiendo degollado a mi madre, mi hermana y mi hermano... Un caso de parricidio del siglo XIX presentado por Michel Foucault, (París: Gallimard, 1973).

${ }^{46}$ Renán Silva Olarte, "En defensa de un positivismo alegre. Michel Foucault en el archivo",... 249.

${ }^{47}$ Lisandro de la Fuente y Luciana Messina, "Bajos fondos del saber.... 8. 
las prácticas de higiene, los manuales de convivencia, en los protocolos de disciplina. Pero lo más importante para Foucault es entender bajo qué tipo de episteme $e^{48}$ se encuentra inscrito un saber: "Quizá se sospeche que esta episteme es algo como una visión del mundo, una tajada de historia común a todos los conocimientos, y que impusiera a cada uno las mismas normas y los mismos postulados, un estadio general de la razón, una determinada estructura de pensamiento de la cual no podrían librarse los hombres de una época, gran legislación escrita de una vez para siempre por una mano anónima". ${ }^{49}$ Es importante señalar que a pesar de su similitud, el concepto episteme para Foucault es muy diferente y no tiene nada que ver con el concepto estructura y por esta similitud se le llamó a Foucault el "último de los estructuralistas". ${ }^{50}$ La diferencia reside en que el concepto estructura remite a un todo coherente, completo y cerrado sobre sí mismo, que permitiera la emergencia de un conocimiento válido y objetivo; la episteme refiere a las formas de pensar, de hablar, de ver de una época, que no están concretizadas por la coherencia sino por las grietas, rupturas y discontinuidades negando por tanto la idea

\footnotetext{
${ }^{48}$ Foucault inaugura un nuevo punto de partida para considerar la historia de los sistemas de pensamiento en occidente, rompiendo verticalmente con el modelo clásico de continuidad-evolución de los saberes en el tiempo. Las epistemes son las disposiciones del saber en la historia del pensamiento que transforman el mundo del discurso, que permiten la aparición de ciertos objetos de conocimiento, de ciertos conceptos, de ciertas modalidades de enunciados, de ciertos temas y de ciertas prácticas de intervención sobre el mundo natural y social que obedecen a ciertas disposiciones del saber de las cuales el hombre no es necesariamente consciente, estas disposiciones del saber las llama Foucault episteme.

${ }^{49}$ Michel Foucault, La arqueología del saber,... 322.

${ }^{50}$ Foucault nunca se declaró estructuralista, jamás pretendió cimentar su discurso en estructuras, a la manera de Saussure o Levy Strauss; su preocupación residía en buscar las leyes de existencia de sus enunciados. Su objetivo fue buscar el desocultamiento del sujeto para poder dar cuenta de la realidad del hombre ante la historia. Para él si las estructuras existiesen serían históricas y no entes absolutos y atemporales. Elías Castro Blanco, "Foucault y los estudios historiográficos",... 100.
} 
de totalización. ${ }^{51}$ Con relación al concepto episteme y su distinción de la historia intelectual, Renán Silva opina lo siguiente:

La idea de abrir al análisis lo que Foucault llamó "el archivo de una cultura", introduciendo nociones en apariencia raras como la de "población de conocimientos discursivos" o la más ambigua de episteme; el intento de describir la cultura intelectual de una época no a través de las obras que hoy consideramos como notables, sino de aquellas que en términos de una época fueron las lecturas corrientes y la expresión de puntos de vista dominantes -lo que mostraba aun más el carácter social de la verdad y la distinción entre el análisis histórico y epistemología-, y por lo tanto la decisión de no limitarse al estudio exclusivo de las obras que la posteridad ha retenido como significativas. ${ }^{52}$

En síntesis, Foucault le propone al historiador en su oficio cotidiano de archivista y manipulador documental, tanto de aquella información que se halla dentro como por fuera de los archivos, intentar primero que todo y, luego de realizar el análisis forense del documento, una ubicación contextual del documento en la episteme donde se generó. ${ }^{53}$

\section{La genealogía y la arqueología en Michel Foucault.}

Es necesario tener bien claro la diferencia entre genealogía y arqueología en Michel Foucault para poder distinguir su utilización e intención metodológica. Lo que hay que tener bien claro es que no son sinónimas y que los críticos han sistematizado la obra del pensador francés en tres

\footnotetext{
${ }^{51}$ Lisandro de la Fuente y Luciana Messina, "Bajos fondos del saber... 10.

${ }^{52}$ Renán Silva Olarte, "En defensa de un positivismo alegre.... 251.

${ }^{53}$ Véase, Renán Silva Olarte, A la sombra de Clío, (Medellín: La Carreta Editores, 2007), 43.
} 
momentos: uno arqueológico, otro genealógico y otro ético, lo que ha sido un error, ya que en lo que se ha denominado periodo genealógico, Foucault ha aplicado igualmente la operación arqueológica y viceversa. Por ejemplo, en Historia de la locura en la época clásica ya se pueden encontrar operaciones genealógicas y arqueológicas; lo mismo se puede decir de Vigilar y castigar y de Historia de la sexualidad 1. La voluntad de saber. Igual se puede decir que El nacimiento de la clínica y Las palabras y las cosas son fuertemente arqueológicas. Por su parte, Historia de la sexualidad 2. El uso de los placeres, e Historia de la sexualidad 3. El cuidado de sí, como bien lo dice la introducción al tomo 2 , es tanto arqueológica como genealógica.$^{54}$ Con relación al concepto arqueología, Fernando Beresñak argumenta lo siguiente:

En primer lugar, cabe mencionar que la noción de arqueología fue tomada por Foucault de Kant, mientras que la noción de genealogía fue elaborada por nuestro autor a partir de la que utilizara Nietzsche (vale decir, de manera bastante similar, aunque no igual, a lo que éste había concebido para la misma). Consideramos que muchas de esas clasificaciones que intentan ubicar a Foucault, o a un período de su obra, en las extrañas categorías de "kantiano", "nietzscheano" u otras, diluyen la posibilidad, seguramente más enriquecedora, de observar el punto donde tanto las lecturas realizadas sobre Kant como aquéllas sobre Nietzsche podrían llegar a encontrarse para ofrecer a Foucault una perspectiva particular. ${ }^{55}$

54 Fernando Beresñak, "Michel Foucault y su metodología históricofilosófica”, ... 16.

${ }^{55}$ Sobre a priori históricos, es la respuesta que nos ofrece el autor francés; sobre una "región privilegiada: a la vez próxima a nosotros, pero diferente de nuestra actualidad (...); es lo que, fuera de nosotros, nos delimita". Claramente jugando entre las dos posibilidades que explicitaba Kant, Foucault intentará dar cuenta de un posible terreno alterno. Esa zona, que no se corresponde ni con la historia de las ideas en tanto no es empírica, ni tampoco con los a priori de la razón en tanto no es estrictamente racional. Fernando Beresñak, "Michel Foucault y su metodología histórico-filosófica",...24. 
En el texto Nietzsche, la genealogía, la historia, Foucault conceptualizará la noción de origen en un sentido más histórico. Los términos alemanes Ursprungy Erfindung Foucault los contrapone y al primero lo concibe como "origen" y al segundo como "invención", y los acoge para desarrollar su metodología histórica. Esa concepción de origen como invención, como artificio, es la que permite a Foucault ubicar a la genealogía en una posición donde queda atrapada en su propia perspectiva y desde allí pueda realizar una operación sobre sí misma, bajo este enfoque, la "emergencia" y la "procedencia" serán el objeto de búsqueda de la genealogía foucaultiana. Teniendo presente que la noción de origen remite a la figura espacial de un punto, las nociones de comienzo y procedencia refieren a una espacialidad más amplia, cuya visibilidad se construye a través de las distancias que conforman las diferencias. En este sentido, la genealogía buscará la dispersión del accidente mostrando la heterogeneidad y las diferencias que conforman la historia. La idea es rastrear y comprobar que en la historia, detrás de las cosas, hay "otra cosa bien distinta”. Veamos que dice Beresñak al respecto:

Debemos situar las nociones de procedencia y emergencia en el marco general del modo de concebir la producción efectiva delos acontecimientos históricos. Así, bajo la óptica foucaulteana, un acontecimiento sería la matriz de fuerzas emergente, producto de la interacción recíproca y -en cierto sentido- caótica de relaciones de fuerzas provenientes de lugares diversos, y con características e historias propias. Cada una de esas fuerzas, hasta (por lo menos) el lugar en el que se entrecruzan con otras, vendrían a constituir y mostrar su específica. El conjunto de historias de cada una de esas fuerzas que conforman la matriz emergente del acontecimiento vendría a ser lo que Foucault llama la procedencia. Ahora bien, cuando esas líneas o fuerzas entran en contacto las unas con las otras se conforma la matriz antes mencionada; y así el estado de fuerzas en 
conflicto que produce lo que Foucault denomina la emergencia del acontecimiento. Así fue reelaborada o reinterpretada la genealogía nietzscheana por Foucault. Mientras que la arqueología toma el material histórico para analizar las condiciones de ejercicio de la función enunciativa del objeto de estudio en un nivel bien determinado, la genealogía toma el material histórico para analizar el conflicto de relaciones de fuerza históricas que ha permitido la producción de los acontecimientos. ${ }^{56}$

Bajo esta perspectiva de análisis nos atrevemos a pensar que la arqueología está más atenta a las condiciones de ejercicio en las cuales determinado saber puede tener lugar; la genealogía está más atenta a la historia entendida como un entramado de relaciones de fuerza en conflicto, inadvertidas y fortuitas. Es importante insistir en que la arqueología y la genealogía no se oponen en lo absoluto, sino por el contrario, se complementan. La arqueología se concentra en las formaciones discursivas y en los proceso de construcción de enunciados, la genealogía se centra en el análisis del movimiento y las formas de configuración de las relaciones de fuerzas y sus estrategias de poder. Foucault juega con dos operaciones en su metodología: una arqueológica y otra genealógica. La primera le sirve para desentrañar las condiciones de ejercicio de determinada función enunciativa, y la segunda para hacer comprensible el complejo volumen de las relaciones de fuerzas históricas. El entramado epistemológico foucaultiano tiene un eje que es la relación saber-poder y con relación a él, Foucault construyó una metodología de interconexión profunda. Esta metodología es la arqueología-genealogía: mientras la primera es aplicada para develar los intríngulis propios de las configuraciones del saber, la segunda lo será para descubrir los armazones del poder y sus prácticas

56 Fernando Beresñak, "Michel Foucault y su metodología históricofilosófica”,... 28. 
sociales. El análisis genealógico focaliza la dimensión de exterioridad de los discursos y busca sus condiciones de existencia en las prácticas discursivas que son, asimismo, prácticas sociales. Las prácticas discursivas producen saberes de distinto tipo que, a su vez, las caracterizan y delimitan sus especificidades. El análisis genealógico ubica las relaciones de fuerza y las complejidades estratégicas de configuración del poder en un momento determinado, y sus efectos sociales traducidos en prácticas científicas que están vinculadas directamente con las configuraciones de un saber. Por ejemplo, con la genealogía no se trata de hacer una historia de la mujer sino construir un análisis del surgimiento de las prácticas de mujerización, no se trata hacer una historia de la criminalidad sino construir un análisis del surgimiento de las prácticas de criminalización, no se trata de hacer una historia del racismo sino construir un análisis del surgimiento de las prácticas de racialización. ${ }^{57} Y$ esto es lo que lo separa de otras formas de hacer historia, que toman a "la mujer", "el criminal" o al "otro", como objetos autoevidentes que están enla "sociedad" esperando que llegue un historiador a contar su "historia excluida". ${ }^{88}$ En suma, es necesario insistir que el análisis arqueológico-genealógico se complementa perfectamente en la metodología foucaultiana, permitiendo construir inferencias y relaciones de encuentros y desencuentros de diferentes aspectos de la historia social. Mientras la arqueología nos sirve para entender la configuración del discurso, la genealogía nos permite analizar las prácticas externas de dicho discurso y cómo estas prácticas se traducen en conductas y comportamientos institucionales donde se les impone a los individuos los postulados de

\footnotetext{
57 Santiago Castro, "La genealogía y la historia: Foucault y el oficio del historiador", Ponencia, Seminario Internacional Intersticios del pensar, Universidad de Cartagena, (Junio de 2013).

${ }^{58}$ Michel Foucault, "El polvo y la nube”, En: La imposible prisión, (Barcelona: Ed. Anagrama,1982).
} 
verdad. Francisco Vásquez plantea lo siguiente respecto al método foucaultiano:

Foucault consideró que este método demostraba que la literatura, la religión, la ciencia histórica, y la filosofía, son grandes tipos de discursos que son fundados por un "hecho discursivo" que no es sustancialmente diferente a todos los demás, ni está más intrínsecamente determinado. Este método, a través de la observación del entrecruzamiento de los saberes, de las prácticas y las instituciones, demostraba que las miradas de estas disciplinas están gobernadas por hipótesis inestables, en donde la agrupación de sus conceptos es consecuencia de lo formado por una práctica discursiva. ${ }^{59}$

\section{Consideraciones finales}

La propuesta historiográfica de Michel Foucault descansa fundamentalmente en la idea de ruptura con la continuidad en la historia propuesta por la historiografía tradicional. Nociones como evolución, tradición, desarrollo se han constituido en grandes unidades discursivas dentro del hipertexto historiográfico tradicional y están incrustadas en la forma de ver y pensar la historia en occidente. Lo que plantea Foucault es deconstruir esta forma de concebir la historia, proponiéndonos librarnos de estas construcciones naturalizadas de largos periodos que dan cuenta de unidades cerradas sobre sí mismas y conectadas por la idea de causalidad. Grandes extensiones de continuidad histórica donde lo discontinuo ocupa un papel menor y opera como un obstáculo que perturba la continuidad de los procesos. Foucault insiste, con relación a la historia tradicional, en que una unidad histórica

${ }^{59}$ Francisco Vásquez García, Foucault: la historia como crítica de la razón, (Barcelona: Montesinos, 2005), 19. 
sobre una época es una construcción realizada desde una perspectiva actual, sobre un conjunto discursivo previo, una operación de construcción de sentido a partir de un efecto de retroversión.

Con relación al sujeto, Foucault no niega que haya sujetos en la historia, por el contrario la historia está repleta de múltiples sujetos. Lo que niega Foucault es que haya sujetos constructores conscientes de devenires históricos o sujetos de la historia. Para Foucault el devenir histórico es una multiplicidad de variados sentidos y direcciones, con múltiples protagonistas anónimos donde ninguno de ellos se puede asimilar a la figura de sujeto de la historia. Pero la concepción de sujeto que se superpone en la historia tradicional ha impedido una revolución epistemológica en el análisis de la historia, soportada en la descentralización del sujeto, propuesta que se ha mantenido desde la obra de Marx, Nietzsche y Freud, que dejaron en evidencia que el hombre no se halla gobernado enteramente por la razón, sospechando de la idea del sujeto libre y consciente de sus actos. Por su parte la historia tradicional ha respondido con la salvaguarda de la soberanía del sujeto contra todos los descentramientos posibles, algo que Foucault rechaza de plano.

Foucault por su parte propone que el sujeto es una construcción realizada en el seno de dispositivos como la familia, la escuela, la fábrica, la cárcel, la sexualidad, el ejército, etc. Construcción que se haya atravesada por dispositivos discursivos con pretensiones de verdad y soportado en saberes con estatus de poder que se traducen en prácticas discursivas específicas que son irrigadas por todo el tejido social. En síntesis, para Foucault el sujeto es un entramado de relaciones históricas.

Para Foucault la verdad es una construcción que surge como efecto de relaciones sociales concretas, rela- 
ciones de fuerza, de poder y resistencia que se intercalan formando una red. Construcción que se produce desde los mismos discursos de saber y de poder, desde las instituciones donde estos discursos operan. Entonces, el objetivo primordial de la arqueología y de la genealogía es desentrañar las articulaciones internas y externas del discurso. La arqueología se ocupará de mostrarnos la composición interior del discurso y sus procesos de construcción de verdad, explicando el entramado de reglas que constituyen los saberes propios de una época. La genealogía se ocupará de los efectos externos del discurso y sus relaciones sociales concomitantes expresadas en prácticas institucionales aplicadas sobre sujetos concretos en una época determinada.

Con relación a la episteme, para Foucault esta sería un especie de recipiente donde todos vivimos sin ser conscientes de él y la arqueología y la genealogía lo que pretenden es revelárnoslo, mostrándonoslo en su configuración íntima y en su expresiones sociales. Entonces, una genealogía es la emergencia de diferentes prácticas sociales de saber y de poder que juntas producen el surgimiento de un fenómeno histórico. Ambas, arqueología y genealogía, operan en el contexto, no de una historia plana y sin grietas, sino en el contexto de una historia discontinua, agujereada y sin sentido alguno.

Con relación al oficio del historiador, el trabajo de Foucault es hecho en archivos como el de cualquier historiador; la diferencia está en el tratamiento del documento. El genealogista propone un tratamiento diferente del documento que, según Foucault, debe ser tratado dentro del contexto epistémico donde se produce. Foucault se opone tanto a la interpretación como a la formalización, dos procedimientos propios de los historiadores. Esta es la propuesta de Foucault: una historia general diseñada y pensada para anteponérsela 
a una historia global totalizante, de un origen fundante y de una causalidad necesaria. Michel Foucault entonces levanta la bandera historiográfica de una contra-historia de múltiples ejes con diferentes concepciones del sujeto, de la verdad y de la historia. La historia como la única manera de producir la eventualización de nuestras verdades del presente, la historia como el pensamiento de la diferencia.

\section{Bibliografía}

Albano, Sergio. Michel Foucault. Glosario epistemológico. Buenos Aires: Editorial Quadrata, 2006.

Beresñak, Fernando. "Michel Foucault y su metodología histórico-filosófica.", Revista Digital Synesis No.2 (Primavera 2011, Mar del Plata): 8-33.

Braudel, Fernand. La historia y las ciencias sociales. Madrid: Alianza, 1970.

Castro Blanco, Elías. "Foucault y los estudios historiográficos.", Criterio Jurídico Garantista No.1. Fundación Universidad Autónoma de Colombia, Barranquilla. (Junio de 2009): 92-109.

Castro Orellana, Rodrigo. "La frase de Foucault: "el hombre ha muerto"”. Alpha No.21. (diciembre de 2005): 225-233.

Castro, Edgardo. Pensar a Foucault: interrogantes filosóficos de La arqueología del saber. Buenos Aires: Biblos, 1995.

Castro, Santiago. "La genealogía y la historia: Foucault y el oficio del historiador". Ponencia, Seminario Internacional Intersticios del pensar, Universidad de Cartagena, Junio de 2013.

Deleuze, Gilles. Foucault. Barcelona: Paidós, 1987. 
De la Fuente, Lisandro y Messina, Luciana. "Bajos fondos del saber. La arqueología como método en Michel Foucault." Litorales Año 2: No. 2 (Agosto 2003): 1-11.

Díaz, Santiago. "Foucault y Veyne. Los usos del acontecimiento en la práctica histórica." A Parte Rei No. 69. (mayo de 2010): 1-20, Documento de internet Serbal.pntic.mec.es/ AParteRei.

García Fanlo, Luis. “QQué es un dispositivo?: Foucault, Deleuze, Agamben.” A Parte Rei No. 74. (marzo 2011): 1-8.

Giraldo Díaz, Reinaldo. "La ética en Michel Foucault o de la posibilidad de la resistencia". Dialogo de saberes No. 29. (diciembre de 2008): 201-213.

Gutiérrez Maldonado, Víctor Iván. "Las transformaciones de las diversas concepciones del sujeto en La arqueología del saber" (tesis de Maestría en Historia, Universidad Autónoma Metropolitana, México, 2012).

Foucault, Michel. El discurso del poder. Buenos Aires: Folios Ediciones, 1992.

Foucault, Michel. Historia de la locura en la época clásica. México: F.C.E., 1967.

Foucault, Michel. La arqueología del saber. Madrid: Siglo XXI, 2006.

Foucault, Michel. Las palabras y las cosas. Madrid: Siglo XXI, 1999.

Foucault, Michel. La verdad y las formas jurídicas. Barcelona: Gedisa, 2005.

Foucault, Michel. Microfísica del poder. Madrid: Ediciones La Piqueta, 1992. 
Foucault, Michel. "Nietzsche, la genealogía, la historia." Sociología No. 5. UNAULA. (diciembre de 1983): 5-23.

Foucault, Michel. Un diálogo sobre el poder y otras conversaciones. Madrid: Alianza Editorial, 1981.

Foucault, Michel. Yo Pierre Riviere, habiendo degollado a mi madre, mi hermana y mi hermano... Un caso de parricidio del siglo XIX presentado por Michel Foucault. París: Gallimard, 1973.

Moreno, José Luís. Convirtiéndose en Foucault. Sociogénesis de un filósofo. Madrid: Montesinos, 2006.

Restrepo Arango, Antonio. Pensar la historia. Medellín: Ediciones Stendhal, 2000.

Silva Olarte, Renán. "En defensa de un positivismo alegre. Michel Foucault en el archivo". Historia y Memoria No. 4 (diciembre de 2012): 225-257.

Silva Olarte, Renán. A la sombra de Clío. Medellín: La Carreta Editores, 2007.

Torres, Javier. Notas para leer al Sujeto en Foucault desde América Latina. Disponible en: http://alainet.org/ active/20042\&lang=es

Vásquez García, Francisco. Foucault: la historia como crítica de la razón. Barcelona: Montesinos, 2005.

\section{Citar este artículo:}

José Wilson Márquez Estrada, "Michel Foucault y la contra-historia", Revista Historia y Memoria No. 08 (enero-junio, 2014): pp. 211-243. 